\title{
Prevalence and Associated Factors of Early Initiation of Complementary Feeding among Infants in Hawassa City, Southern Ethiopia
}

Fekadu Bekele ( $\square$ fekbek18@gmail.com )

Hawassa Health Science College

Berhan Meshesha

Hawassa University

Bethlehem Eshetu

Hawassa University

\section{Research Article}

Keywords: Complementary feeding, Early initiation of complementary feeding, Infant and young child feeding, Southern Ethiopia

Posted Date: September 14th, 2021

DOl: https://doi.org/10.21203/rs.3.rs-877539/v1

License: (a) (1) This work is licensed under a Creative Commons Attribution 4.0 International License. Read Full License 


\section{Abstract}

Background: Nutrition in infancy and early childhood is a critical determinant of health outcomes and productivity of the individual throughout his/her life years. Thus, World Health Organization and United Nations Children's Fund recommend initiation of complementary foods at 6 months to ensure optimal child growth and development. In Ethiopia, compliance with infant and young child feeding recommendations is low despite its adoption of different international policies and guidelines. Thus, the aim of this study was to assess the magnitude and associated factors of early initiation of complementary feeding among infants in Hawassa City, Southern Ethiopia, 2021.

Methods: A community-based cross-sectional study was conducted in Hawassa City, in January 2021. A systematic random sampling technique was applied to recruit 543 mothers who had infants aged 6 to 12 months. A structured and interviewer-administered questionnaire was used to collect data. by six. A multivariable logistic regression analysis was applied to identify factors associated with the early initiation of complementary feeding. Adjusted odds ratio with corresponding $95 \%$ confidence interval was calculated to show the strength of association.

Result: A total of 543 mothers/caregivers of infants were interviewed face to face, giving a response rate of $97 \%$. Approximately $38 \%$ of mothers initiated complementary foods before six months of age. After adjusting for confounders, maternal employment status [AOR (95\%Cl): $4.72(2.84,7.87)]$ and postnatal care checkup [AOR (95\%Cl): $1.92(1.24,2.97)]$ were significantly associated with early initiation of complementary feeding.

Conclusion: A high proportion of mothers initiated complementary feeding before six months of infant's age. Postnatal care checkup and mother's occupational status were significantly associated with early initiation of complementary feeding. Thus, increasing the coverage of postnatal care utilization and creating mother-friendly workplaces for breastfeeding mothers is of paramount importance to realize appropriate complementary feeding practices.

\section{Background}

Complementary feeding (CF) is the process of initiating foods when breast milk alone is no longer sufficient to fulfill the nutritional requirements of infants, and therefore other solid and liquid foods are needed along with breast milk. Here the term complementary feeding is used purposefully to underline the role of complementary foods since they are given to complement breast milk but not to replace it [1].

In order to ensure optimal child growth and development, World Health Organization (WHO) and United Nations Children's Fund (UNICEF) recommend exclusive breastfeeding (EBF) for the first 6 months of life. Thereafter, nutritionally adequate and safe complementary foods should be introduced at 6 months. This means the infants should be given nothing but breast milk until they are six months old $[2,3]$. 
Therefore, complementing breast milk before 6 months of age is unnecessary, and it is one of the important determinants of malnutrition among young children. Malnutrition accounts for $60 \%$ of infant and young child deaths. Where two-thirds of those deaths attributed to sub-optimal child feeding practices and infectious diseases [4,5].

According to UNICEF, nearly 200 million under 5 children suffered from stunting or wasting globally. At the same time, at least 340 million suffered from hidden hunger. The greatest burden of malnutrition is shouldered by children from the poorest and most marginalized communities of the world. However, the number of stunted children has declined in all continents, except in Africa [6].

The major negative aspects of early initiation of complementary feeding (EICF) include an increased risk of infection/illness, with consequent impaired growth and an increased risk for later obesity. The children who started CF early also face long-term physical, educational and economic setbacks [7, 8].

Ethiopian Ministry of health adopted infant and young child feeding practices (IYCF) strategy in 2004. It recommends infants should be exclusively breastfed for the first six months of life without any additional liquid or solid foods. Thereafter, it should be accompanied by the consumption of nutritionally adequate, safe, and appropriate complementary foods that help meet the nutritional requirement of the children [9].

Despite the above recommendation, compliance to infant and young child feeding recommendations has been reported to be low. For example, according to the Ethiopia Demographic and health survey (EDHS) report of 2016 many infants were fed with other liquids such as water (17\%), non-milk liquids (5\%), and other kinds of milk (5\%) before reaching age 6 months. Hence, there is a long way to go as the country has high stunting (38\%), underweight (24\%), and wasting $(10 \%)$ rates [10].

However, the practice of EBF among children under 6 months has consistently increased from $49 \%$ in 2005 to $52 \%$ in 2011 , and $58 \%$ in 2016 . But, the median duration of exclusive breastfeeding, the time by which half of the children have started complementary foods, is still low - 2.3 and 3.1 months in 2011 and 2016 respectively [10-12].

In Ethiopia, the prevalence of EICF practices has wide variations in different areas. A survey done in Debre Berhan town indicated that the prevalence of EICF practices was 31.4\% [13]. Another community-based study by Agedew et al. showed that $59.6 \%$ of mothers introduced complementary foods before six months [14]. Similarly, in 2015, a study conducted in Pawie District of Benshangul Gumuz Region reported the prevalence of EICF to be 22.5\% [15]. While a study carried out in Bishoftu town among infants aged less than six months revealed the prevalence of EICF to be $32.9 \%$; with a median age of 3 months [16].

In Ethiopia, two separate studies conducted on EICF showed that maternal age, postnatal care (PNC) checkup, maternal health status, delayed initiation of breastfeeding, maternal occupational status, place of delivery, and lack of knowledge on the optimum duration of EBF were associated with EICF $[14,16]$. 
Even though some studies $[14,16,17]$ were conducted on the early initiation of complementary feeding in Ethiopia, To the best of our knowledge, there are no published articles determining the prevalence and associated factors of EICF in Hawassa. Due to differences in cultural practices, occupation, access to healthcare and education, it is likely that findings from other parts of Ethiopia cannot be directly inferred to the city. Thus, this study will be of paramount importance in revealing up-to-date information on the prevalence and associated factors of EICF practices being experienced in the city. Therefore, the aim of this study was to assess the magnitude and associated factors of EICF among infants in Hawassa City, Southern Ethiopia, 2021.

\section{Methods}

\section{Study setting and design}

A community-based cross-sectional study was conducted in Hawassa City, in January 2021. Hawassa is a city located on the Eastern shores of Lake Hawassa, at the base of Tabor Mountain. The Hawassa City is $273 \mathrm{~km}$ South of Addis Ababa, the capital city of Ethiopia. The city is administratively divided into eight sub-cities, which are further divided into 32 kebeles (kebele is the smallest administrative unit). The Central Statistical Agency projection of the city population for 2018 was 397,654, of which $51.4 \%$ were males and $48.6 \%$ were females. There were 13 public health facilities ( 10 health centers and 3 hospitals) in the city.

\section{Sample size and sampling procedure}

The sample size was calculated by using a single population proportion formula; by assuming a $95 \%$ confidence level $(\mathrm{Za} / 2=1.96), 5 \%$ margin of error $(\mathrm{d}=0.05)$, and design effect (Deff) of 1.5 . The proportion of EICF is $32.9 \%$ as reported by G.G Deme et al. in Bishoftu Town, Oromia region [16].

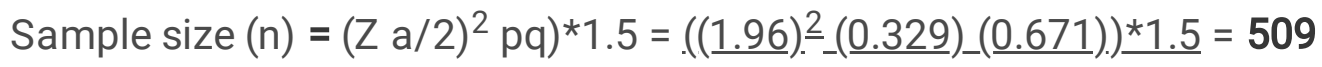

$$
\mathrm{d} 2(0.05)^{2}
$$

Which was further increased to 560 to account a predicted $10 \%$ non-response rate, i.e., the final sample size $=509+51=560$.

From 32 kebeles, eight kebeles were selected by using a lottery method. The total number of infants aged 6 to 12 months was obtained from family folder records of Health Extension Workers (HEWs). After allocating the sample size to each kebele proportionally, the sampling interval was calculated for each kebele by dividing the number of infants by the sample size allocated to each kebele. Then, mother-infant pairs in the selected kebeles were recruited by using a systematic random sampling (SRS) technique. The initial household was selected by applying a lottery method. In the case of two or more eligible participants in the same household, a lottery method was applied to select one. Whenever an eligible infant was not available during the data collection period, a replacement technique from the closest 
household was used. The next diagram (Figure 1) shows a more detailed impression of the sampling procedure.

\section{Data collection tool and procedure}

A pre-tested, structured, and interviewer-administered questionnaire was used to collect data. The questionnaire was developed based on the EDHS report of 2016 [10], and other peer-reviewed published studies [13-21, 23]. It was originally developed in English and translated into Amharic. The Amharic questionnaire was used to collect data after being pre-tested on $5 \%(28)$ of mothers in two non-selected kebeles prior to the actual data collection period. The questionnaire was checked for its clarity, understandability, and completeness. Important modifications were made based on the pretest results. The data collection process was undertaken by six trained diploma nurses who had previous exposure to data collection. Finally, the Amharic version was translated back to English to verify the consistency of the questionnaire.

\section{Study variables and operational definition}

Early initiation of complementary feeding was the outcome variable. It was defined as early initiation if a baby had received any kind of food or fluids in addition to breast milk before six months of infancy. But, it didn't include oral rehydration salts (ORS), drops, therapeutic syrups or any kind of medicines. It was assessed by asking mothers an approximate age of the infants during they had introduced complementary foods to them.

The independent variables that were identified to be potential predictors of EICF are grouped as follows:-

Socio-economic and Demographic factors:- maternal age, marital status of the mother, parental educational status, parental occupational status, ethnicity, religion, monthly household income, and sex of the infant.

Obstetric and healthcare-related factors:- place of delivery, counseling on CF, mode of delivery, parity, ANC attendance, PNC checkup, maternal health status, maturity and birth order of the infant.

Traditional and Cultural factors:- removing colostrum and pre-lacteal feeding.

Knowledge related:- previous experience on $\mathrm{CF}$, knowledge on the recommended duration of $\mathrm{CF}$ initiation, and ownership of TV/radio.

\section{Data processing and analysis}

After completion of the data collection process, the data were coded and double entry was undertaken by using Epidata version 4.6. The data were exported to SPSS version 25 for cleaning and analysis. Bivariable logistic regression was undertaken to examine the association between dependent and 
individual independent variables and it was reported by using Crude Odds Ratio (COR) and P-value. Variables having a p-value less than 0.2 in the bivariable logistic regression analysis were entered into the multivariable logistic regression model to determine the independent association between EICF and its predictors. In the multivariable logistic regression model, variables having a P-value of $<0.05$ were considered as statistically significant and an Adjusted Odds Ratio (AOR) with a 95\% confidence interval was reported to show the magnitude of association. A Hosmer and Lemeshow significance test was applied to check model fitness, considering $\mathrm{P}>0.05$ as a criterion and it was found to be 0.57 .

\section{Ethical approval}

The ethical clearance was obtained from the institutional review board (IRB) of Hawassa University, College of Medicine and Health Sciences before the fieldwork. A formal letter of permission to undertake the study was sought from the Health Department of Hawassa City Administration. Then, Health Department was requested to write a formal letter to the respective kebele leaders. After clearly explaining the aim and importance of the study, verbal informed consent was sought from the participants. Participation of all respondents in the study was voluntary and the right not to participate was respected. Furthermore, an anonymous questionnaire was used to assure the confidentiality of the information.

\section{Results}

\section{Socio-demographic characteristics of study participants}

A total of 543 mothers/caregivers of infants aged 6 to 12 months were interviewed face to face giving a response rate of $97 \%$. Of the total 543 respondents, 512 (94.3\%) were biological mothers of infants. Whereas the remaining 31 (5.7\%) were caregivers such as fathers, grandmothers, and sisters.

Almost all (97.8\%) of mothers were living in union with their husbands. The mean age of the respondents was 29 ( \pm 5.6 SD, Standard Deviation) years. Of the total respondents, $151(27.8 \%)$ attended primary school, whereas 19 (3.5\%) of them can't read and write. Inline to this, husbands of 519 ( 98\%) mothers had attended formal education. Among these, 162 (3.50\%) and 251 ( 47\%) had attended secondary and tertiary levels respectively. Just about $30 \%(n=164)$ of mothers were housewives while around $45 \%$ $(n=238)$ of fathers were government employees. From a total of 543 infants included in the study, 278 (51.2\%) were females (See Table 1 at the end of the document text file).

\section{Infant feeding practices}

\section{Breastfeeding practices}

All infants were breastfed at some point in their life. However, only $62.1 \%$ of infants were exclusively breastfed for the first six months of life. Inline with the recommended practice, the proportion of infants who were breastfed within 24 hours before data collection was $97.2 \%$. Five hundred twenty $(95.8 \%)$ 
infants fed colostrum. Nearly, $3 \%(n=15)$ of the infants were given pre-lacteal feeds within the first day of life. On average, there was only a slight difference in the mean duration of exclusive breastfeeding between male $(5.08 \pm 1.4)$ and female $(5.03 \pm 1.4)$ infants.

\section{Complementary feeding practices}

Approximately $38 \%$ of mothers initiated complementary foods to their infants before six months of age. Nearly, seven out of ten $(69.2 \%)$ infants were given fluids from a bottle with a nipple one day before data collection; a practice which is discouraged (Table 2).

Table 2. Feeding practices of infants aged 6-12 months in Hawassa City, Southern Ethiopia, 2021 ( $n=543)$

\begin{tabular}{|llll|}
\hline Variable & Category & Frequency (n) & Percentage (\%) \\
\cline { 2 - 4 } Infant ever breastfeed & Yes & 543 & 100.0 \\
\cline { 2 - 4 } Initiation of breastfeeding & No & 0 & 0 \\
\cline { 2 - 4 } Removal of colostrum & Within one hour & 466 & 85.8 \\
\cline { 2 - 4 } & After one hour & 77 & 14.2 \\
\hline Prelacteal feeding & Yes & 23 & 4.2 \\
\cline { 2 - 4 } Infant currently breastfeeding & No & 520 & 95.8 \\
\cline { 2 - 4 } & Yes & 15 & 2.8 \\
\cline { 2 - 4 } & No & 528 & 97.2 \\
\hline Bottle feeding & No & 15 & 97.2 \\
\cline { 2 - 4 } & Yes & 376 & 2.8 \\
\cline { 2 - 4 } & No & 167 & 30.8 \\
\cline { 2 - 4 } & &
\end{tabular}

The mean age of introduction to complementary foods was $5 \pm 1.4$ months. The highest age at which complementary foods were introduced to the infants was seven months and the lowest being one month (Figure 2).

Reasons for initiation of complementary foods 
The major reasons that accounted for early initiation of complementary foods were mothers' perception of insufficiency of breast milk to satisfy the infant's need $(n=71,34.5 \%)$ and advice of elder mothers $(n=42,20.4 \%)$. Likewise, the study participants were asked for their reasons to initiate complementary foods at 6 months of age which is the recommended practice. The majority $(n=146,43.3 \%)$ responded that they were counseled by health professionals not to initiate complementary foods until six months of infancy. Whereas $(n=105,31.2 \%)$ responded that they were advised by elder mothers to do so (Figure 3 ).

\section{Obstetric and healthcare related factors}

Almost all (97\%) mothers had a history of ANC follow up at least once during pregnancy with the index child. Around $86 \%(n=464)$ of respondents stated that their partners were participating in the daily care of their infants like feeding them. The majority $(95.6 \%)$ of mothers gave birth to their index child in a health facility. Slightly higher than nine-tenths of infants were born after 37 completed weeks of gestation.

Cesarean deliveries accounted for $24.7 \%$ of the total deliveries. Mothers having two under five children (including the index child) accounted for $47 \%$ of the study participants. The majority of the mothers (72.0\%) visited PNC clinics. Sixteen percent of respondents stated that they had a history of chronic disorders like elevated blood pressure and epilepsy. Approximately, $94 \%$ of respondents had mass media access (owned radio or television). (Table 3 ).

Table 3. Obstetric and healthcare related services utilization among mothers with infants aged 6-12 months in Hawassa City, Southern Ethiopia, 2021 (543). 


\begin{tabular}{|c|c|c|c|}
\hline Variable & Category & Frequency & Percentage \\
\hline \multirow[t]{2}{*}{ ANC visit } & Yes & 527 & 97.1 \\
\hline & No & 16 & 2.9 \\
\hline \multirow[t]{2}{*}{ Place of delivery } & Home or elsewhere & 24 & 4.4 \\
\hline & Health facility & 519 & 95.6 \\
\hline \multirow[t]{3}{*}{ Maturity of infant } & Preterm & 19 & 3.5 \\
\hline & Term & 496 & 91.3 \\
\hline & Post-term & 28 & 5.2 \\
\hline \multirow[t]{2}{*}{ Parity [Number of live births] } & One live birth & 235 & 43.3 \\
\hline & Two or more live births & 308 & 56.7 \\
\hline \multirow[t]{2}{*}{ Mode of delivery } & Vaginal & 409 & 75.3 \\
\hline & Caesarian section (C/S) & 134 & 24.7 \\
\hline \multirow[t]{2}{*}{ Mass media exposure } & Yes & 512 & 94.3 \\
\hline & No & 31 & 5.7 \\
\hline \multirow[t]{2}{*}{ Support of father } & Yes & 467 & 86.0 \\
\hline & No & 76 & 14.0 \\
\hline \multirow[t]{2}{*}{ Number of under five children } & One & 287 & 52.9 \\
\hline & Two or more & 256 & 47.1 \\
\hline \multirow[t]{2}{*}{ PNC } & Yes & 391 & 72.0 \\
\hline & No & 152 & 28.0 \\
\hline \multirow[t]{2}{*}{ Chronic medical illness } & Yes & 88 & 16.2 \\
\hline & No & 455 & 83.8 \\
\hline
\end{tabular}

Nearly, $67 \%$ of mothers were counseled about the recommended time of CF initiation during ANC/delivery/PNC by healthcare providers (Figure 4).

\section{Awareness and knowledge of respondents on complementary feeding practices}

This study showed that almost all (98.3\%) study participants had ever heard about complementary feeding. Their main sources of CF information were friends/neighbors (32.0\%) and television (27.4\%). Slightly more than $97 \%$ of mothers stated six months as the ideal time to introduce foods or fluids in 
addition to breast milk. Around $76 \%$ of the study participants responded that " the child should continue breastfeeding up to at least two years of age after the introduction of complementary foods."

The study participants were also asked about a variety of foods consumed by the infant in the past 24 hours. On average, $40.5 \%$ of infants received complementary foods from less than four groups which is below the recommended minimum dietary diversity. Breastfeeding on demand which is the recommended regime was reported by almost half $(49.7 \%)$ of respondents. The majority $(61.3 \%)$ of respondents stated that the consistency of an infant's food at six months should be semi-solid, with $29.5 \%$ saying liquid.

Mothers who had given birth to two or more children were also asked about their previous experience of complementary feeding on the immediately older sibling. Accordingly, the mean age of introduction of complementary foods to the immediately older siblings of the index infants was $4.9 \pm 1.3$ months (Table 4).

Table 4. Awareness and knowledge of mothers with infants aged 6-12 month on complementary feeding practices in Hawassa City, Southern Ethiopia, 2021 ( $n=543)$. 


\begin{tabular}{|c|c|c|c|}
\hline Variables & Category & $\begin{array}{l}\text { Frequency } \\
\text { (n) }\end{array}$ & $\begin{array}{l}\text { Percentage } \\
\text { (\%) }\end{array}$ \\
\hline \multirow[t]{2}{*}{ Ever heard about CF } & Yes & 534 & 98.3 \\
\hline & No & 9 & 1.7 \\
\hline \multirow[t]{4}{*}{ Source of information $(n=534)$} & Radio & 63 & 11.8 \\
\hline & Television & 149 & 27.9 \\
\hline & Friends/neighbors & 174 & 32.6 \\
\hline & $\begin{array}{l}\text { Health care } \\
\text { providers }\end{array}$ & 148 & 27.7 \\
\hline \multirow{3}{*}{$\begin{array}{l}\text { The recommended time to introduce } \\
\text { foods/fluids }\end{array}$} & Before 6 months & 12 & 2.2 \\
\hline & At 6 month & 529 & 97.4 \\
\hline & After 6 months & 2 & 0.4 \\
\hline \multirow[t]{4}{*}{ The recommended time to stop breastfeeding } & One year & 26 & 4.8 \\
\hline & Two years & 415 & 76.4 \\
\hline & Three years & 99 & 18.2 \\
\hline & I don't know & 3 & 0.6 \\
\hline \multirow{4}{*}{$\begin{array}{l}\text { Frequency of breastfeeding after introduction of } \\
\text { foods/fluids }\end{array}$} & On demand & 270 & 49.7 \\
\hline & 1-2 times & 35 & 6.4 \\
\hline & 3-4 times & 192 & 35.4 \\
\hline & $\geq 5$ times & 46 & 8.5 \\
\hline \multirow[t]{2}{*}{ Diversity of infant's food } & Poor & 220 & 40.5 \\
\hline & Good & 323 & 59.5 \\
\hline \multirow[t]{3}{*}{ Consistency of infant's food at 6 months } & Liquid & 160 & 29.5 \\
\hline & Semi-solid & 333 & 61.3 \\
\hline & Solid & 50 & 9.2 \\
\hline \multirow[t]{2}{*}{ Previous experience of mothers on CF $(n=306)$} & Early initiated & 143 & 46.7 \\
\hline & $\begin{array}{l}\text { Initiated at } \geq 6 \\
\text { months }\end{array}$ & 163 & 53.3 \\
\hline
\end{tabular}




\section{Factors associated with early initiation of complementary feeding}

Bivariabe analysis showed that maternal educational status, maternal occupation, age of mother, birth order, PNC visit, parity, support of the father, counseling on appropriate CF practices during ANC /delivery//PNC visit, number of under five children, mass media exposure and knowing the recommended time of CF initiation were crudely associated with EICF. But in the adjusted analysis, only two variables (maternal occupation and PNC checkup) were significantly associated with the independent variable (Table 5).

Table 5. Factors associated with early initiation of complementary feeding among infants aged 6-12 months in Hawassa City, Southern Ethiopia, 2021 ( $n=543$ ). 


\begin{tabular}{|c|c|c|c|c|c|}
\hline \multirow[t]{2}{*}{ Variable } & \multirow[t]{2}{*}{ Category } & \multicolumn{2}{|c|}{$\begin{array}{l}\text { Early initiation of } \\
\text { CF }\end{array}$} & \multirow[t]{2}{*}{$\begin{array}{l}(C O R \text { 95\% } \\
C I)\end{array}$} & \multirow[t]{2}{*}{ AOR (95\%Cl) } \\
\hline & & Yes & No & & \\
\hline \multirow[t]{2}{*}{ Age [respondent] } & $\leq 30$ & 155 & 210 & 1 & 1 \\
\hline & $>30$ & 51 & 127 & $\begin{array}{l}0.54 \\
(0.37,0.80)\end{array}$ & $\begin{array}{l}1.01 \\
1.85)\end{array}$ \\
\hline \multirow[t]{4}{*}{$\begin{array}{l}\text { Educational status } \\
\text { [mother] }\end{array}$} & $\begin{array}{l}\text { No formal } \\
\text { education }\end{array}$ & 6 & 13 & 1 & 1 \\
\hline & Primary & 47 & 104 & $\begin{array}{l}0.98(0.35 \\
2.73)\end{array}$ & $\begin{array}{l}1.02(0.32 \\
3.25)\end{array}$ \\
\hline & Secondary & 89 & 83 & $\begin{array}{l}2.32(0.84 \\
6.4)\end{array}$ & $\begin{array}{l}1.75(0.55 \\
5.55)\end{array}$ \\
\hline & Tertiary & 64 & 137 & $\begin{array}{l}1.01(0.37, \\
3.78)\end{array}$ & $\begin{array}{l}0.56(0.17 \\
1.81)\end{array}$ \\
\hline \multirow[t]{2}{*}{ Occupation [mother] } & Housewife & 34 & 130 & 1 & 1 \\
\hline & Employed & 172 & 207 & $\begin{array}{l}3.18(2.07 \\
4.88)\end{array}$ & $\begin{array}{l}4.72(2.84 \\
7.86)^{*}\end{array}$ \\
\hline \multirow[t]{3}{*}{ Birth order } & First & 115 & 120 & 1 & 1 \\
\hline & Second & 55 & 116 & $\begin{array}{l}0.50(0.33 \\
0.75)\end{array}$ & $\begin{array}{l}1.09(0.58 \\
2.04)\end{array}$ \\
\hline & Third and above & 36 & 101 & $\begin{array}{l}0.37(0.24 \\
0.59)\end{array}$ & $\begin{array}{l}1.53(0.62 \\
3.75)\end{array}$ \\
\hline \multirow[t]{2}{*}{ Counseling on CF } & Yes & 129 & 232 & 1 & 1 \\
\hline & No & 77 & 105 & $\begin{array}{l}1.32(0.92, \\
1.90)\end{array}$ & $\begin{array}{l}1.07(0.71 \\
1.62)\end{array}$ \\
\hline \multirow[t]{2}{*}{ Parity } & Primipara & 115 & 120 & 1 & 1 \\
\hline & Multipara & 91 & 217 & $\begin{array}{l}0.44(0.31 \\
62)\end{array}$ & - \\
\hline \multirow[t]{2}{*}{ Support [Father] } & Yes & 170 & 297 & 1 & 1 \\
\hline & No & 36 & 40 & $\begin{array}{l}1.57(0.97 \\
2.56)\end{array}$ & $\begin{array}{l}1.53(0.85 \\
2.75)\end{array}$ \\
\hline \multirow[t]{2}{*}{ PNC visit } & Yes & 128 & 263 & 1 & 1 \\
\hline & No & 78 & 74 & $\begin{array}{l}2.17(1.48, \\
3.18)\end{array}$ & $\begin{array}{l}1.92(1.24 \\
2.97)^{\star}\end{array}$ \\
\hline \multirow[t]{2}{*}{ Number of U5C } & One & 131 & 156 & 1 & 1 \\
\hline & More than one & $\begin{array}{l}75 \\
\text { ge } 13 / 2\end{array}$ & 181 & $0.49(0.35$ & $0.93(0.50$ \\
\hline
\end{tabular}




\begin{tabular}{|llllll|}
\hline Know right time of CF & & & & $0.70)$ & $1.72)$ \\
& Yes & 197 & 332 & 1 & 1 \\
\cline { 2 - 6 } & No & 9 & 5 & $\begin{array}{l}3.03(1.0, \\
9.18)\end{array}$ & $\begin{array}{l}2.07(0.56, \\
\text { Media exposure }\end{array}$ \\
& Yes & 187 & 325 & 1 & 1 \\
\cline { 2 - 6 } & No & 19 & 12 & $2.75(1.31$, & $1.37(0.57$, \\
\hline
\end{tabular}

\section{NB. ${ }^{*} p<0.05$ (Significant factors)}

\section{Discussion}

This study was conducted to assess the magnitude and associated factors of early initiation of complementary feeding. It showed that the prevalence of EICF was approximately $38 \%$ in the city. It is lower when compared to studies conducted in Gondar (47.5\%), Jimma Arjo (52.1\%) and Kamba District $(59.6 \%)[14,17,18]$. The lower prevalence observed in this study could be owing to differences in access to education, health care and the urban setting of the study.

However, it is higher than findings of surveys conducted in Bishoftu town (32.9\%), Goba district (28.7\%), Fiche town (23\%), Debre Berhan (31.4\%), Mekelle City (19.7\%), Tahtay- Maichew District [30.2], EDHS $2016(42 \%)$ and WHO recommendation for good practice of CF (<20\%) $[1,13,16,19-21]$. The possible explanation for the higher prevalence of EICF in this study might be attributed to differences in the study population, sample size and study setting.

This study identified two factors (mother's occupation and PNC visit) that were associated with ECF. The maternal occupation had a considerable role in EICF in the first 6 months. Employed mothers were approximately 4.7 times more likely to introduce complementary foods early to their infants than housewives [AOR $(95 \% \mathrm{Cl})=4.72(2.84,7.87]$. This finding is consistent with studies conducted in different parts of Ethiopia; Mekelle City, Kamba District, Bishoftu town, Tahtay-Maichew, Gondar town and Goba district of Oromia region $[14,16,17,19-21]$.

Likewise, this study is also in agreement with a study conducted in four Anglophone West African countries [22]; which revealed a negative association between housewives and EICF compared to employed mothers. The possible reason for this might be due to the fact that housewives stay longer with their infants at home; whereas, employed mothers return to work as they are granted short time for maternity leave. As a result, housewives initiate CF to their infants earlier than their counterparts. 
The findings of this study also indicated that mothers who did not attend PNC had a $92 \%$ increased risk of initiating complementary foods early when compared to mothers who attended PNC [AOR $(95 \% \mathrm{Cl})=$ $1.92(1.24,2.97)]$. This result is compatible with the findings from Bishoftu town, Soro district of Hadiya Zone and Pawie District of Benshangul Gumuz Region [15, 16, 23]. Indeed, PNC visit has an important role in improving maternal knowledge and changing negative attitude towards implementation of the recommended IYCF practices. This might be due to the effect of health education on IYCF that the mothers receive from health professionals during their PNC checkups.

\section{Conclusion}

A high proportion of mothers initiated complementary foods before six months of infancy. PNC checkups and mother's occupational status were significantly associated with the early initiation of complementary foods to the infants. The median age of initiation of complementary foods is six months.

To enhance adherence to the recommended IYCF practices, increasing the coverage of PNC utilization and modifying regulations related to the time granted for maternal leave should be addressed by the government at a policy level. In addition to this, every health facility should take initiative structures that enhance nutrition education on IYCF to mothers at every contact point, especially during PNC checkups.

Home-based counseling of mothers on IYCF by HEWs gives another opportunity for encouraging them to optimally feed their infants. On top of that, local health authorities should give emphasis on enhancing the capacity of healthcare providers in performing this role. Mother-friendly workplaces should be created for breastfeeding mothers as employed mothers need special attention to practice EBF.

\section{Declarations}

\section{Acknowledgments}

We are indebted to the Health Department of Hawassa City, chairpersons, and Health Extension Workers (HEWs) of the selected kebeles for their support in providing baseline information required by the study. Our heartfelt gratitude also goes to data collectors and study participants for their cooperation and willingness to be part of this study.

\section{Authors' contributions}

Conceptualization: $\mathrm{FB}, \mathrm{BM}, \mathrm{BE}$ 
Data curation: $\mathrm{FB}, \mathrm{BM}, \mathrm{BE}$

Formal analysis: $\mathrm{FB}$

Investigation: $\mathrm{FB}, \mathrm{BM}, \mathrm{BE}$

Methodology: FB, BM, BE

Project administration: FB

Resources: FB

Software: FB, BE

Supervision: FB

Validation: $F B, B M, B E$

Visualization: $\mathrm{FB}, \mathrm{BM}, \mathrm{BE}$

Writing - original draft: $\mathrm{FB}, \mathrm{BM}, \mathrm{BE}$

Writing - review \& editing: FB, BM, BE

\section{References}

1. WHO \& UNICEF (2003). Global strategy for infant and young child feeding. Geneva: World Health Organization

2. World health organization. Infant and child feeding, Geneva. 2019. https://www.who.int/newsroom/factsheets/detail/infant-and-young-child-feeding

3. UNICEF (2019). Monitoring the situation of children and women, Infant and young child feeding: UNICEF, New York. https://data.unicef.org/topic/nutrition/infant-and-young-child-feeding/

4. PAHO/WHO. Guiding principles for complementary feeding of the breastfed child. Division of Health Promotion and Protection. Food and Nutrition Program. Pan American Health Organization/ World Health Organization. Washington/Geneva; 2003.

5. WHO. World Health Organization complementary feeding practice fact sheet. 2014.

6 UNICEF (2019). The State of the World's Children 2019.Children, Food and Nutrition: Growing well in a changing world. UNICEF, New York

7. Victoria CG, Adair L, Fall C et al. (2008) Maternal and child undernutrition: consequences for adult health and human capital. Lancet 371, 340-357 
8. UNICEF global databases, 2015, based on MICS, DHS and other nationally representative surveys

9. Federal Ministry of Health and Family Health Department Ethiopia, National Strategy for Infant and Young Child Feeding, Federal Ministry of Health, Family Health Department Ethiopia, Addis Ababa, Ethiopia, 2004

10. Central Statistical Agency/CSA/Ethiopia and ICF. 2016. Ethiopia Demographic and Health Survey 2016. Addis Ababa, Ethiopia, and Rockville, Maryland, USA: CSA and ICF

11. Central Statistical Agency [Ethiopia] and ORC Macro. 2006. Ethiopia Demographic and Health Survey 2005. Addis Ababa, Ethiopia, and Calverton, Maryland, USA: Central Statistical Agency and ORC Macro.

12. Central Statistical Agency [Ethiopia] and ICF International. 2012. Ethiopia Demographic and Health 25 Survey 2011. Addis Ababa, Ethiopia and Calverton, Maryland, USA: Central Statistical Agency and ICF International.

13. Tilahun, G., Degu, G., Azale, T. et al. Prevalence and associated factors of timely initiation of breastfeeding among mothers at Debre Berhan town, Ethiopia: a cross-sectional study. Int Breastfeed J 11, 27 (2016) doi:10.1186/s13006-016-0086-5.

14. Agedew, E., Demisse, M., Misker, D. and Hailu, D. (2014) Early Initiation of Complementary Feeding and Associated Factors among 6 Month to 2 Years Young Children, in Kamba Woreda, Southwest Ethiopia. Journal of Nutrition \& Food Science, 4, 6. http://dx.doi.org/10.4172/2155-9600.1000314.

15. Ayana, D., Tariku, A., Feleke, A. et al. BMC Res Notes (2017) 10: 335. https://doi.org/10.1186/s13104017-2663-0.

16. Deme, G.G., Bekele, S.A., Argaw, M.D. and Berhane, Y. (2015) Factors Associated with Early Initiation of Complementary Feeding in Bishoftu Town, Oromia, Ethiopia. Open Access Library Journal, 2: e1949.http://dx.doi.org/10.4236/oalib.1101949

17. Mengistu Berhanu, Workie Zemene, and Mengistu Mekonnen, _Prevalence and Associated Factors of Nonexclusive Breastfeeding to Infants within the First 6 Months in Gondar Town, Northwest Ethiopia, 2014,|l Advances in Nursing, vol. 2015, Article ID 142319, 7 pages, 2015.

https://doi.org/10.1155/2015/142319

18. Tamiru, D., Belachew, T., Loha, E. et al. Sub-optimal breastfeeding of infants during the first six months and associated factors in rural communities of Jimma ArjoWoreda, Southwest Ethiopia. BMC Public Health 12, 363 (2012) doi:10.1186/1471-2458-12-363

19. Setegn, T., Gerbaba, M. \& Belachew, T. Determinants of timely initiation of breastfeeding among mothers in GobaWoreda, South East Ethiopia: A cross sectional study. BMC Public Health 11, 217 (2011) doi:10.1186/1471-2458-11-217 
20. Reda EB, Teferra AS, Gebregziabher MG. Time to initiate complementary feeding and associated factors among mothers with children aged 6-24 months in Tahtay Maichew district, northern Ethiopia. BMC Res Notes. 2019;12 (1):17. Published 2019 Jan 14. doi:10.1186/s13104-019-4061-2

21. Shumey, A., Demissie, M. \& Berhane, Y. Timely initiation of complementary feeding and associated factors among children aged 6 to 12 months in Northern Ethiopia: an institution-based cross-sectional study. BMC Public Health 13, 1050 (2013) doi:10.1186/1471-2458-13-1050

22. Issaka Al, Agho KE, Page AN, Burns P, Stevens GJ, Dibley MJ. Determinants of early introduction of solid, semi-solid or soft foods among infants aged 3-5 months in four Anglophone West African countries. Nutrients. 2014;6(7):2602-18.

23. Yohannes B, Ejamo E, Thangavel T, Yohannis M. Timely initiation of complementary feeding to children aged 6-23 months in rural Soro district of Southwest Ethiopia: a cross-sectional study. BMC Pediatr. 2018;18 (1):17. Published 2018 Jan 31. doi:10.1186/s12887-018-0989-.

\section{Figures}

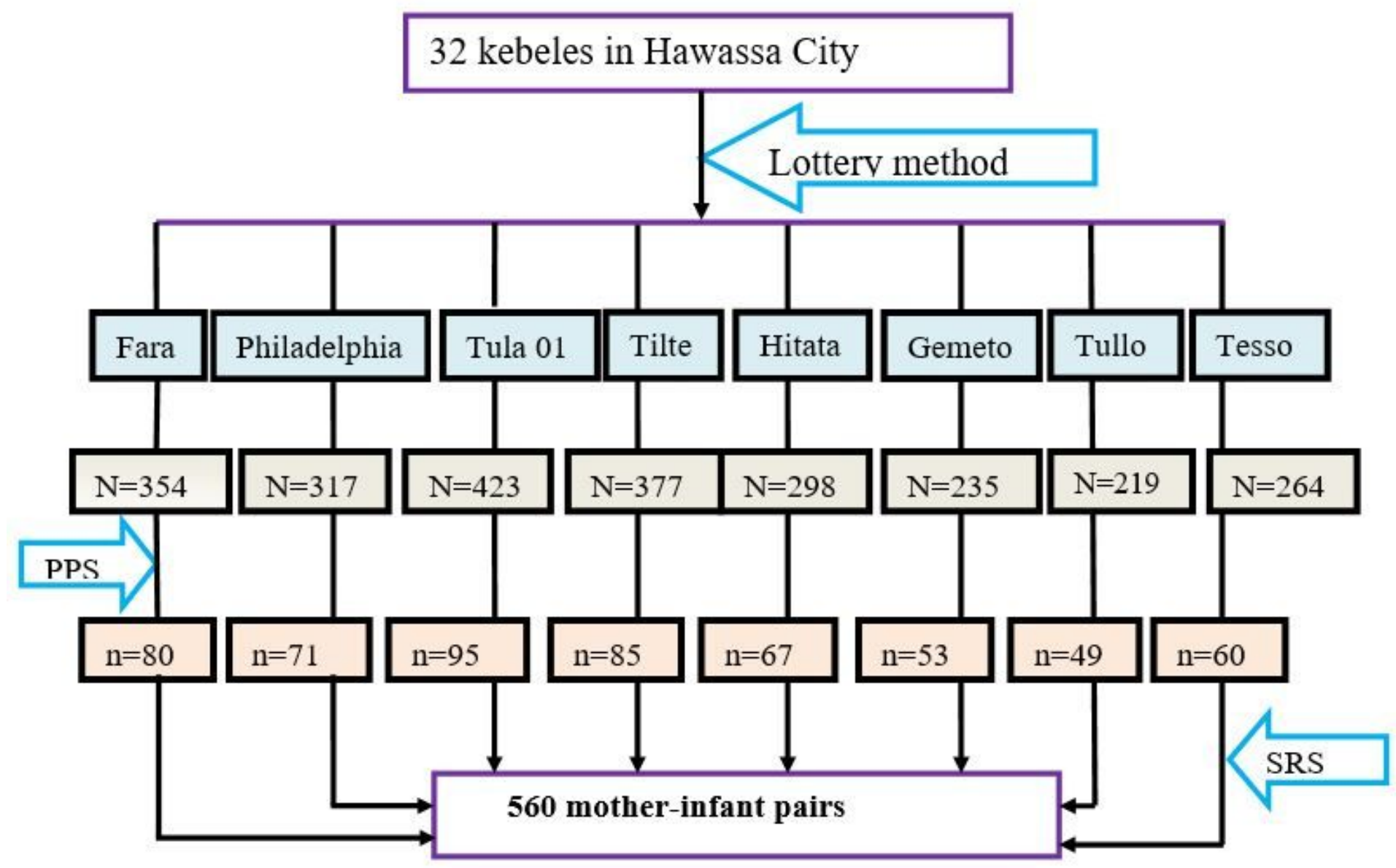

Figure 1 
Schematic illustration of sampling procedure of mother-infant pairs in Hawassa City, Southern Ethiopia, 2021

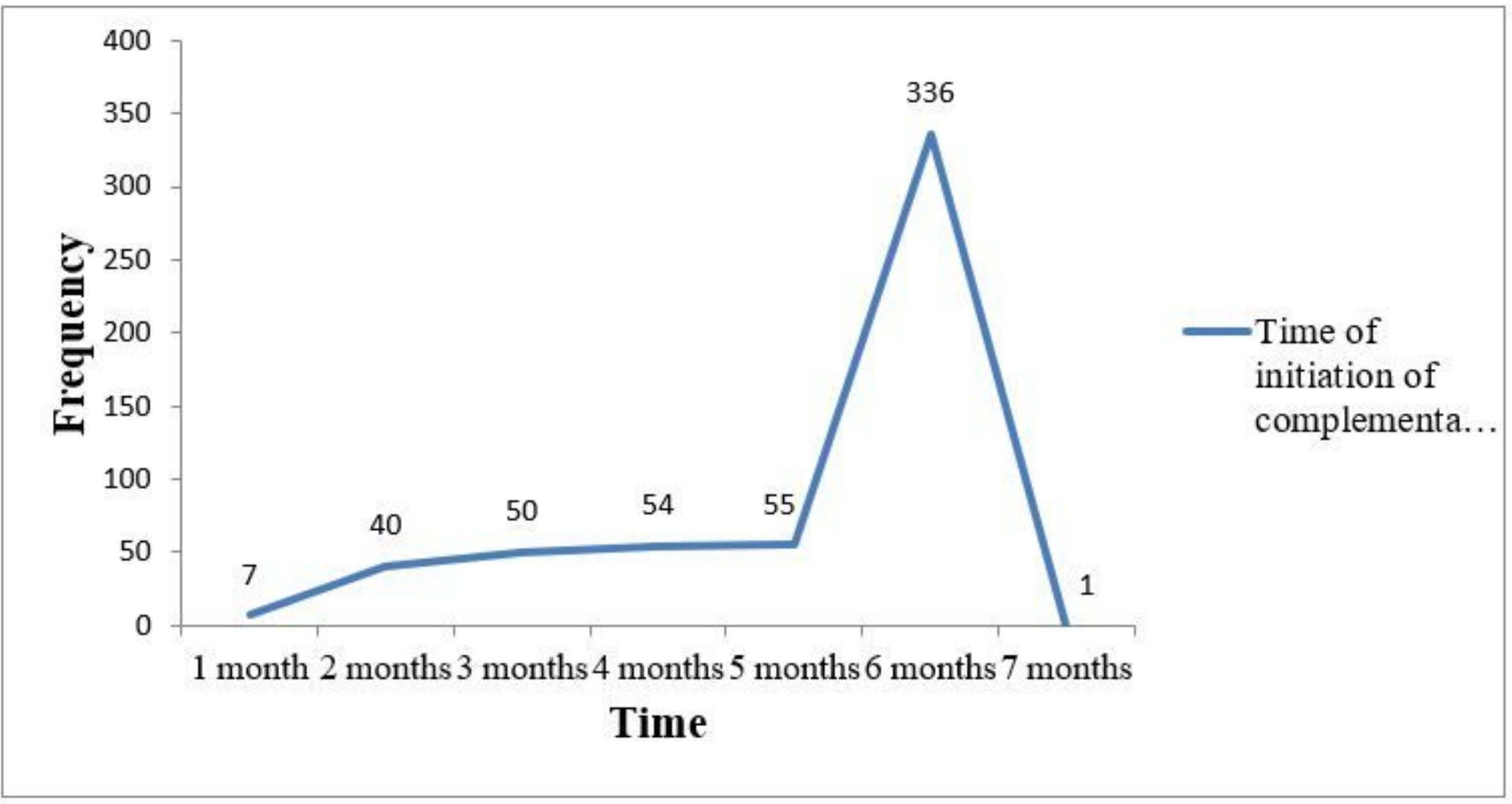

Figure 2

Time of initiation of complementary feeding among infants aged 6-12 months in Hawassa City, Southern Ethiopia, 2021. 


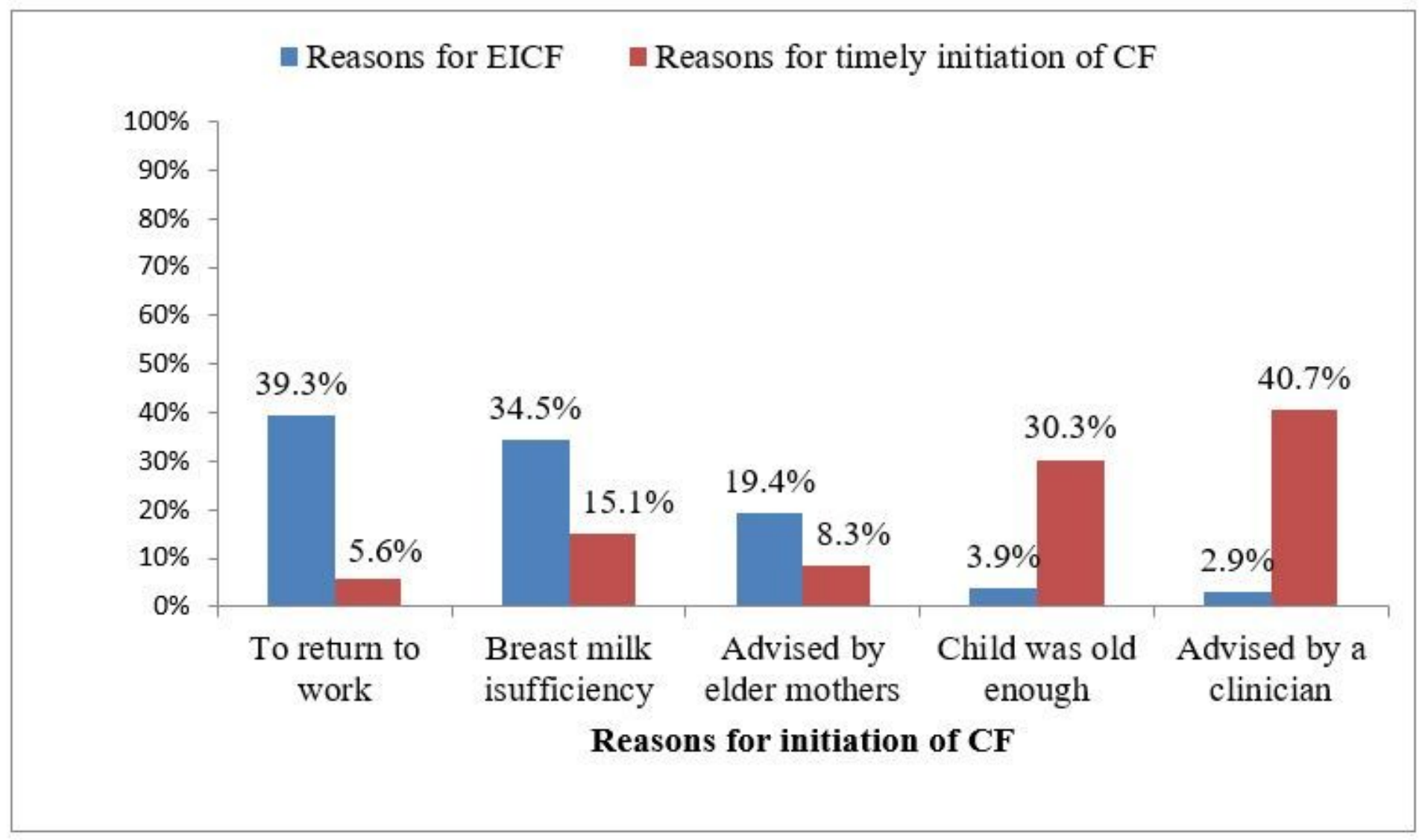

\section{Figure 3}

Reasons for early and timely initiation of complementary feeding in Hawassa City, Southern Ethiopia, 2021 